\title{
基于小分子的锌离子苂光分子探针研究进展
}

\author{
刘 敏 ${ }^{a}$ 谭慧龙 ${ }^{a}$ 刘治国 ${ }^{a}$ 王 维 ${ }^{b}$ 曾文涁*, \\ ( ${ }^{a}$ 中南大学药学院 长沙 410013) \\ ( ${ }^{b}$ 中南大学湘雅三医院放射科 长沙 410013)
}

\begin{abstract}
摘要 锌离子在生物体的大脑活动、基因转录和免疫功能等生理、病理过程中扮演着重要角色, 选择性识别和检测锌 离子具有十分重要的生物学意义. 菼光检测法在选择性、灵敏度、实时原位监测等方面具有独特的优势，应用荧光法 检测胞内 $\mathrm{Zn}^{2+}$ 是近年来研究热点之一. 文中按照三种不同的荧光作用机制(光诱导电子转移、分子内电荷转移和荧光能 量共振转移)进行分类和总结, 介绍了近 10 年来锌离子荧光分子探针的研究进展, 概述了各类型重要荧光探针的设计、 性能及其生物应用，评述了探针的结构和检测性能之间的关系，最后展望了锌离子苂光探针的发展趋势和应用前景. 关键词 锌离子; 荧光; 探针; 小分子
\end{abstract}

\section{Advances in Fluorescent Probes Based on the Small Molecules for $\mathrm{Zn}^{2+}$}

\author{
Liu, Min ${ }^{a} \quad$ Tan, Huilong $^{a} \quad$ Liu, Zhiguo ${ }^{a} \quad$ Wang, Wei ${ }^{b} \quad$ Zeng, Wenbin*,a \\ ( ${ }^{a}$ School of Pharmaceutical Sciences, Central South University, Changsha 410013) \\ ( ${ }^{b}$ Department of Radiology, Third Xiangya Hosipital of Central South University, Changsha 410013)
}

\begin{abstract}
Zinc ion $\left(\mathrm{Zn}^{2+}\right)$ plays an essential role in many physiological processes of the organism, such as brain activities, gene transcription and immune function, as well as some pathological processes and so on, therefore selective recognition and detection of $\mathrm{Zn}^{2+}$ are of important biological significance. Fluorescence technology has unique advantages such as high selectivity, sensitivity, low cost, real-time and in situ monitoring, thus it has become one of the most important sensing technologies for zinc ion and a hot topic area in recent years to imaging $\mathrm{Zn}^{2+}$ in cells. Herein, the latest progresses in the last 10 years of fluorescent molecular probes based on the small molecules for $\mathrm{Zn}^{2+}$ are reviewed. These important fluorescent probes are classified according to three different mechanisms action (PET, ICT and FRET). The designs of molecular structure, sensing mechanism and biological applications of these probes are introduced. In addition, the structure and property relationships are elucidated. Finally, the problems and the developing trends in this field are also discussed.
\end{abstract}

Keywords zinc ions; fluorescence; molecular probe; small molecule

锌是人体中含量仅次于铁的一种重要微量元素, 广 泛分布于细胞和体液中. 它直接参与体内细胞的生长发 育、生殖、组织修复、基因转录、金属酶催化、神经传 递、免疫功能等生命代谢过程 ${ }^{[1,2]}$. 研究报道 $\mathrm{Zn}^{2+}$ 与阿尔 茨海默病 $(\mathrm{AD}) 、$ 癫㾁症、缺血性中风和贞儿腹泻症等疾 病有着密切关系 ${ }^{[3]}$. 锌是第 II 副族过渡金属，具有 $3 \mathrm{~d}^{10} 4 \mathrm{~s}^{2}$ 结构, 常用的紫外光谱、圆二色谱、核磁共振、 电子顺磁共振、循环伏安法等分析方法均不适用于高效
测定 $\mathrm{Zn}^{2+}$. 苂光法具有操作简便、灵敏度高、选择性好 等优点，与显微镜连用可实现对细胞内外金属离子高时 空分辨率的成像，这是其它传统分析方法无法比拟的 ${ }^{[4]}$. 快速、便捷地检测锌离子的荧光分子探针备受关注，特 别是对于细胞、组织和活体中锌离子的定量分析和分子 显像，近年来已成为生物学、化学、分子影像学、临床 医学等领域的一个研究热点. 本文将综述近年来小分子 锌离子荧光探针的研究进展，按照三种苂光作用机制:

\footnotetext{
* E-mail: wbzeng@csu.edu.cn

Received January 8, 2013; revised February 22, 2013; published online March 7, 2013.

Project supported by the National Natural Science Foundation of China (Nos. 30900377, 81271634), the National Science Foundation for Distinguished Young Scholars of Hunan Province (No. 12JJ1012), the Education for New Century Excellent Talents (No. NCET-10-0800) and the Research Fund for the Doctoral Program of Higher Education (No. 20120162110070).

国家自然科学基金(Nos. 30900377, 81271634)、湖南省自然科学杰出青年基金(No. 12JJ1012)、教育部新世纪优秀人才计划(No. NCET-10-0800)及教育 部高等学校博士学科点专项科研基金(No. 20120162110070)资助项目.
} 
光诱导电子转移(PET)、分子内电荷转移 (ICT)、苂光能 量共振转移(FRET)进行分类和总结, 着重介绍各类型 荧光探针的设计、性能及其生物应用, 探讨探针的结构 和检测性能之间的关系.

\section{1 基于光诱导电子转移(Photoinduced Elec- tron Transfer, PET)机理}

在苂光分子探针的设计中, PET 是最常见的机理之 - ${ }^{[5]}$. 典型的 PET 荧光分子探针是由含电子供体的识别 基团, 通过一间隔基团和苂光团相连而构成. 在未结合 客体前，识别基团中的非键电子在光照后将向激发态荧 光团转移, 由于识别基团的 HOMO 轨道能级高于荧光 团的 HOMO 轨道能级, 致使荧光团被激发到 LUMO 轨 道的电子无法直接回到基态，而是通过识别基团 HOMO 轨道返回, 发生 PET 过程, 荧光淬灭; 一旦识别 基团与客体相结合, 则该识别基团的氧化电位升高, 使 其 HOMO 轨道能级降低, PET 过程受到抑制, 甚至被完 全阻断，被激发的电子可以直接返回到基态，荧光恢复 (图 1). 因此, 基于 PET 机理的 $\mathrm{Zn}^{2+}$ 荧光分子探针一般 是通过荧光从无到有或从弱到强的信号变化来达到检 测 $\mathrm{Zn}^{2+}$ 目的.


excited fluorophore free receptor excited fluorophore bond receptor

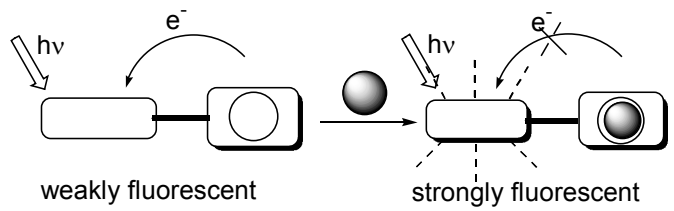

图 1 基于 PET 作用机理的示意图

Figure 1 Schematic illustration of the mechanism based on PET

基于 PET 作用机制的锌离子荧光分子探针大致可 分为: 喹啉类、荧光素类、香豆素类、氟硼荧染料类、 荎酰亚胺类、苯并唑类、亚氨二乙酸类、近红外染料类 等.

\section{1 喹啉类}

1987 年 Frederickson 等 ${ }^{[6]}$ 首次报道了基于喹啉的 TSQ (6-甲氧基-8-对甲苯磺酰胺喹啉，6-methoxy-8- $p$ toluenesulfonamido-quinoline)分子探针, 其作为一种组 织荧光染色剂可用于神经细胞内的 $\mathrm{Zn}^{2+}$ 成像. 此后, 不 断有文章报道了以喹啉为母核具有高选择性和灵敏性 的 $\mathrm{Zn}^{2+}$ 荧光分子探针 ${ }^{[7 \sim 10]}$, 而其中以 8-羟基喹啉或 8-
氨基喹啉为母体设计合成的 $\mathrm{Zn}^{2+}$ 荧光分子探针发展迅 速 ${ }^{[11]} .2007$ 年江华等 ${ }^{[12]}$ 报道了一个以 8 -差基喹啉为母核 的锌离子苂光探针 $\mathbf{1}$, 它是以 DPA $[N, N$-二(2-吡啶甲基) 胺, $N, N$-di-2-picolylamine]作为 $\mathrm{Zn}^{2+}$ 识别基团, 并且在 8 位羟基处引入一个羧基，一方面增加了化合物的水溶 性，另一方面提高了探针对 $\mathrm{Zn}^{2+}$ 亲和力. 配位 $\mathrm{Zn}^{2+}$ 后 1 的荧光增强 14 倍, 发射波长从 $425 \mathrm{~nm}$ 红移至 $438 \mathrm{~nm}$, 研究结果表明, 1 可作为检测细胞内极低浓度 $\mathrm{Zn}^{2+}$ 的荧 光分子探针, $K_{\mathrm{d}}$ 值达到 $(0.45 \pm 0.02) \mathrm{fmol} / \mathrm{L}$ (表 1). 2011 年 郭子建等 ${ }^{[13]}$ 以 8 -磺酰胺哇啉为母核设计合成了一个能 准确定量 $\mathrm{Zn}^{2+}$ 的苂光分子探针 2 , 游离的探针 $\mathbf{2}$ 在 302 $\mathrm{nm}$ 波长处有强吸收, 向中性 HEPES 缓冲溶液加入 $\mathrm{Zn}^{2+}$ 后, 该处吸收强度降低, 但在 $360 \mathrm{~nm}$ 处出现新的强 吸收峰, 其发射谱中心在 $532 \mathrm{~nm}$ 波长处. 通过滴定和单 晶衍射证明 2 与 $\mathrm{Zn}^{2+} 1: 1$ 比率螯合, 其中 DPA 中的三 个 $\mathrm{N}$ 原子和喹啉环上的 $\mathrm{N}$ 原子都参与了金属离子的配 位.
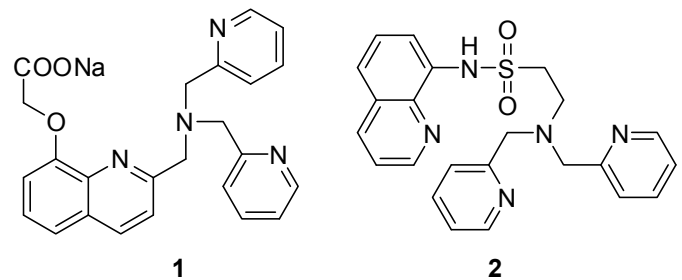

2012 年 Chan 等 ${ }^{[14]}$ 以四氨基安替吡啉为识别基团连 接在 8-氨基喹啉母核上合成了一个选择性好和灵敏度 高的 $\mathrm{Zn}^{2+}$ 苂光分子探针 3. 螯合 $\mathrm{Zn}^{2+}$ 后，探针 3 荧光增 强 10.6 倍, 并在紫外灯下可看见明显的绿色荧光. 探针 配位 $\mathrm{Zn}^{2+}$ 后破坏了喹啉 $\mathrm{N}$ 原子与酰胺 $\mathrm{H}$ 原子之间的分 子内氢键，导致荧光加强; 3 与 $\mathrm{Zn}^{2+}$ 螯合能形成一个刚 性的环状结构 3a, PET 过程发生受阻是 $\mathrm{Zn}^{2+}$ 诱导荧光增 强的另一个原因. 该课题组利用探针 3 成功地进行了活 体细胞中 $\mathrm{Zn}^{2+}$ 的菼光显像研究.

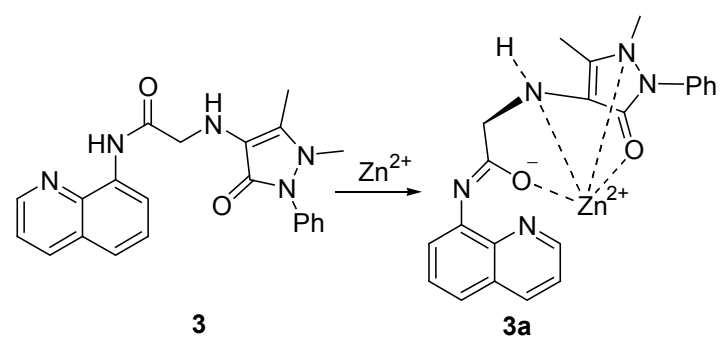

\section{2 荧光素类}

荧光素类染料作为荧光团具有较大的摩尔消光系 数, 在水溶液中苂光量子产率也比较高, 目前以苂光素 为荧光团基于 PET 机理的锌离子荧光分子探针的报道 
较多. 早在 2000 年 Nagano 等 ${ }^{[15]}$ 报道了以苂光素为苂光 才, DPEA $[N, N$-二(2-吡啶甲基)乙二胺, $N, N$-di-(2picolyl)ethylenediamine]为识别基团的 $\mathrm{Zn}^{2+}$ 荧光分子探 针 4 和 5. 两者的最大吸收波长和发射波长分别为 492 和 $514 \mathrm{~nm}$, 加入 $\mathrm{Zn}^{2+}$ 后荧光强度分别提高 17 倍和 51 倍. 两个探针分子在中性缓冲液中的 $\mathrm{Zn}^{2+}$ 的 $K_{\mathrm{d}}$ 分别达 到了 0.78 和 $2.7 \mathrm{nmol} / \mathrm{L}$. 值得一提的是, 由于识别基团 在苯环上的 5 位或 6 位取代, 使探针 4 和 5 对金属离子 的选择性产生了较大差别: 加入 $\mathrm{Zn}^{2+}$ 后探针 4 的荧光增 强倍数比探针 $\mathbf{5}$ 小很多, 而在 $\mathrm{Cd}^{2+}$ 存在条件下其选择性 却优于探针 5. 这主要取决于苯环上的羧基是否参与了 金属离子的螯合: 探针 4 的识别基团在 5 号位, 其结构 中的羧基参与了离子的螯合, 与 DPEA 四个氮原子组成 的螯合部分空腔较大, 结合的 $\mathrm{Zn}^{2+}$ 不是那么牢固, PET 并未完全阻断, 使其荧光增强较弱, $\mathrm{Cd}^{2+}$ 的离子半径比 $\mathrm{Zn}^{2+}$ 大, 能够比 $\mathrm{Zn}^{2+}$ 结合空腔更紧, 但是 $\mathrm{Cd}^{2+}$ 的参与并 不能改变识别基团的 HOMO 能量, 所以 PET 过程仍然 发挥作用; 而探针 5 结构中的羧基在 6 号位, 由于位阻 无法参与配位螯合，只有 DPEA 四个氮原子与金属离子 配位, 所以加入 $\mathrm{Zn}^{2+} 、 \mathrm{Cd}^{2+}$ 都出现苂光加强现象.

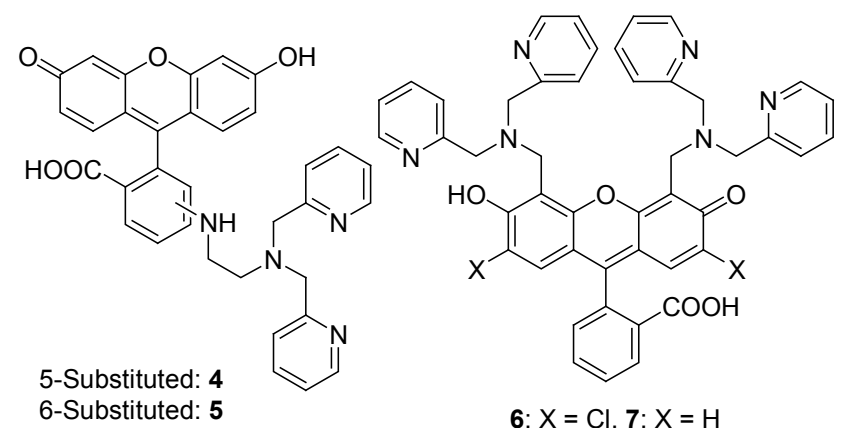

2001 年 Lippard 等 ${ }^{[16]}$ 以荧光素为荧光团, DPA 为 $\mathrm{Zn}^{2+}$ 识别基团设计合成了荧光分子探针 6 和 7. 在没有 $\mathrm{Zn}^{2+}$ 存在的 PIPES 溶液中, 探针 6 和 7 的苂光量子产率 分别为 0.38 和 0.25 , 加入 $25 \mu \mathrm{mol} / \mathrm{L} \mathrm{Zn}^{2+}$ 后荧光量子产 率分别达到 0.87 和 0.92 , 两者的最大激发波长都蓝移 8 $\mathrm{nm}$, 蓝移的主要原因是因为荧光素分子中的羟基作为 电子给体参与了 $\mathrm{Zn}^{2+}$ 配位. 碱土金属 $\mathrm{Ca}^{2+}$ 和 $\mathrm{Mg}^{2+}$ 对探 针 6 和 7 无响应, 但过渡态二价金属离子 $\mathrm{Cu}^{2+}, \mathrm{Mn}^{2+}$, $\mathrm{Ni}^{2+}, \mathrm{Co}^{2+}, \mathrm{Fe}^{2+}$ 使两者发生菼光淬灭. 另外, 由于 DPA 含有两个吡啶氮原子, 使得其 $\mathrm{pKa}$ 值较大, 极易质子化, 对溶液 $\mathrm{pH}$ 较敏感, 且探针的背景荧光较强 $\left(6: \mathrm{p} K_{\mathrm{a}}=8.4\right.$, $\left.\Phi=0.38 ; 7: \mathrm{p} K_{\mathrm{a}}=9.4, \Phi=0.25\right)$. 为解决此类探针苂光 背景强、 $\mathrm{pH}$ 敏感等问题, Lippard 课题组陆续报道了一 系列 $\mathrm{Zn}^{2+}$ 荧光探针, 解决方案主要是通过在荧光素母 核上取代极性基团或者对识别基团 DPA 进行修饰 ${ }^{[17 ~ 20], ~}$ 而这类荧光探针的一个共同点都是基于 PET 机理响应
$\mathrm{Zn}^{2+}$.

在 2005 年 Lippard 等 ${ }^{[21]}$ 以苂光素染料为苂光团, 分 别在呫吨环上引入一个和两个 8 -氨基喹啉基团作为 $\mathrm{Zn}^{2+}$ 识别基团，合成了荧光分子探针 8 和 9 . 其中探针 8 在加入过量的 $\mathrm{Zn}^{2+}$ 后, 吸收光谱从 $505 \mathrm{~nm}$ 蓝移至 498 $\mathrm{nm}$, 荧光增强 42 倍, $\mathrm{pH}$ 7 12 范围内稳定性较好, $\mathrm{pH}$ 5.5 时荧光强度最大. 探针 9 比探针 8 多一个淬灭基团, 所以其荧光背景非常弱 $(\Phi=0.005$, 比探针 8 小 5 倍), 结 合 $\mathrm{Zn}^{2+}$ 后, 其吸收光谱蓝移 $10 \mathrm{~nm}$, 两个探针在结合 $\mathrm{Zn}^{2+}$ 后都表现出吸收光谱蓝移，说明了菼光素染料母核 中酚氧原子参与了 $\mathrm{Zn}^{2+}$ 螯合, 改变了母核中 $\pi$ 共轭系 统. 激光共聚焦和双光子荧光显微研究揭示探针 9 具有 良好细胞膜透性, 能够响应细胞中的 $\mathrm{Zn}^{2+}$, 但是相比于 探针 6 和 7,9 对 $\mathrm{Zn}^{2+}$ 亲和力低, 所以探针 9 只能响应细 胞中较高浓度的 $\mathrm{Zn}^{2+}$, 这进一步说明了探针对响应离 子的亲和性是细胞检测中的一个重要参数.


近期 Lippard 等 ${ }^{[22,23]}$ 又报道了一类以吡啶/吡嗪为识 别基团, 菼光素为荧光团的 $\mathrm{Zn}^{2+}$ 苂光分子探针 10. 相比 于探针 6, 10 具有 $\mathrm{p} K_{\mathrm{a}}$ 值更小 $\left(\mathrm{p} K_{\mathrm{a}}=6.24\right)$, 苂光背景更低, 锌离子选择性更高等优点. 另外运用探针 10 可实现运 用一种新策略定量检测水溶液中 $\mathrm{Zn}^{2+}$ 含量, 因为该类 探针以一种特别的方式与 $\mathrm{Zn}^{2+}$ 结合: 当游离或以 $1: 1$ 比率结合 $\mathrm{Zn}^{2+}$ 时，探针 10 的荧光很弱，但是当以 $1: 2$ 比率结合 $\mathrm{Zn}^{2+}$ 时, 其苂光显著增强; 而当向含有 $\mathrm{Zn}^{2+}$ 的 水溶液逐滴加入探针 10 时, 则在 $10 / \mathrm{Zn}^{2+}$ 为 $1: 2$ 时苂光 达到最强, 继续滴加则出现苂光强度下降. 苂光素母核

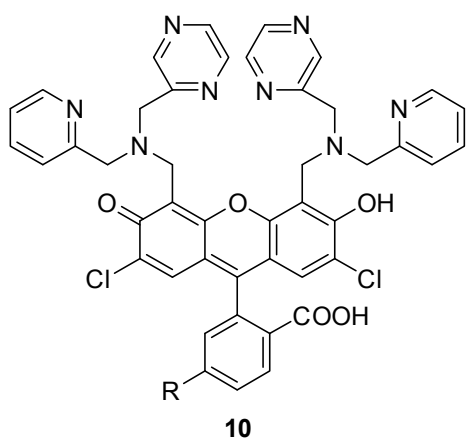


上苯环的 6 位可以用羧基或酯基修饰，并不会显著改变 探针 10 结合 $\mathrm{Zn}^{2+}$ 后的光学特性, 另外还可以提高探针 的水溶性和细胞膜透性, 从而实现选择性监测细胞内、 外 $\mathrm{Zn}^{2+}$ 的目的.

\section{3 香豆素类}

香豆素作为荧光团具有荧光量子产率高, Stokes 位 移大, 光稳定性好等优点. 2003, 2004 年 Bruckner等 ${ }^{[24,25]}$ 选择 4-氨甲基-6,7-二甲氧基香豆素为苂光团, 设计合成 了鳌合诱导荧光增强型 $\mathrm{Zn}^{2+}$ 荧光探针 11 和 12. 向中性 HEPES 缓冲溶液中加入 $\mathrm{Zn}^{2+}$ 后, 探针 11 荧光增强 4.4 倍, $\mathrm{Zn}^{2+}$ 的结合比率为 $1: 1, K_{\mathrm{d}}$ 为 $1 \mu \mathrm{mol} / \mathrm{L}$, 但是该探针 鳌合锌离子的动力学性质不是很理想, 加入过量的锌离 子后, 需要 $300 \mathrm{~min}$ 才能达到平衡, 这限制了其在生物 学上的应用. 探针 12 在 $\mathrm{Zn}^{2+}$ 加入后荧光增强 22 倍, 苂 光量子产率则由游离时的 0.04 提高到 0.88 . 探针 $\mathbf{1 2}$ 在 $\mathrm{pH} 4.0 \sim 11.0$ 范围内稳定性好, 可作为大鼠 $\mathrm{GH} 3$ 和 H4IIE 肿瘤细胞中 $\mathrm{Zn}^{2+}$ 的苂光显像剂.<smiles></smiles>

11<smiles>COc1cc2oc(=O)cc(CN(Cc3ccccn3)Cc3ccccn3)c2cc1OC</smiles>

12
2010 年杨小峰等 ${ }^{[26]}$ 在 7 羟基香豆素母核 8 位上引 入一个氨基腿基团构建了基于西弗碱类的 $\mathrm{Zn}^{2+}$ 荧光探 针 13, 其氨基脲结构中的 $\mathrm{C}=\mathrm{N}$ 键配位 $\mathrm{Zn}^{2+}$ 后, 香豆素 母核由于 PET 过程发生受到阻碍, 导致荧光恢复(13a, Eq. 1). 与 $\mathrm{Zn}^{2+}$ 结合前, 探针 $\mathbf{1 3}$ 的最大吸收和发射波长 分别是 416 和 $483 \mathrm{~nm}$, 结合 $\mathrm{Zn}^{2+}$ 后, 最大吸收谱和发射 谱相应地蓝移 9 和 $26 \mathrm{~nm}$, 而探针分子中的羟基参与 $\mathrm{Zn}^{2+}$ 螯合配位, 使 13a 的荧光团共轭体系变短, 这是吸 收谱和荧光谱发生蓝移的主要原因. 该探针对 $\mathrm{Zn}^{2+}$ 具 有较高的选择性.<smiles>CCOC(=O)c1cc2ccc(O)c(/C=N/NC(N)=O)c2oc1=O</smiles>

13

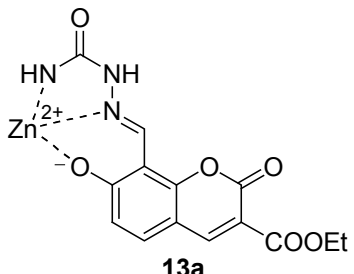

$13 a$

\section{4 氟嗍苂(BODIPY)类}

BODIPY 染料是一类新兴的荧光染料, 具有高的荧 光量子产率、高的摩尔消光系数、良好的光稳定性、对 $\mathrm{pH}$ 不敏感等优点. 2004 年 Nagano 等 ${ }^{[27]}$ 报道了以 BOD-
IPY 为母体合成的 $\mathrm{Zn}^{2+}$ 荧光分子探针 14 , 结合 $\mathrm{Zn}^{2+}$ 后, 探针 14 苂光增强 30 倍, 苂光量子产率增加近 20 倍, 在 生理条件下，碱金属或碱土金属浓度达到 $2.5 \mathrm{mmol} / \mathrm{L}$ 对 探针 14 选择性识别 $\mathrm{Zn}^{2+}$ 无影响, $\mathrm{Mn}^{2+}, \mathrm{Co}^{2+}, \mathrm{Ni}^{2+}, \mathrm{Cu}^{2+}$ 诱导 14 产生微弱的苂光增强. 2005 年彭孝军等 ${ }^{[28]}$ 以 BODIPY 为苂光团, DPA 为识别基团设计合成了 $\mathrm{Zn}^{2+}$ 苂 光分子探针 15, 其 $509 \mathrm{~nm}$ 处的苂光强度在探针结合 $\mathrm{Zn}^{2+}$ 后明显增强，荧光量子产率则由未结合锌离子时的 0.077 增至 0.875 , 该荧光探针有较低的 $\mathrm{pKa}$ 值和解离常 数 $\left(\mathrm{p} K_{\mathrm{a}}=2.1, K_{\mathrm{d}}=1.0 \mathrm{~nm}\right.$, 表 1$)$.

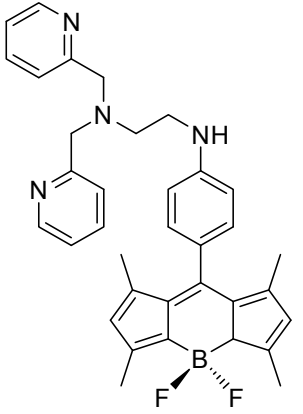

14

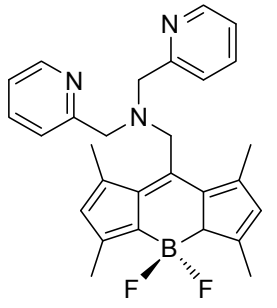

15

\section{5 萗酰亚胺类}

䒬酰亚胺荧光团具有光化学性质稳定、激发及发射 波长较长、Stokes 位移大、对 $\mathrm{pH}$ 不敏感等优点，已被 广泛应用于设计各种金属离子分子探针. 2005 年钱旭红 等 ${ }^{[29]}$ 报道了基于 4 -氨基荎酰亚胺衍生物的 $\mathrm{Zn}^{2+}$ 苂光探 针 16. 游离的探针 16 因为苯胺上氮原子的孤对电子到 4-氨基荟酰亚胺的 PET 作用使其本身的荧光很弱. 加入 $\mathrm{Zn}^{2+}$ 后，探针 16 的荧光增强 6 倍，苂光量子产率提高到 0.19 , 滴定实验表明 16 与 $\mathrm{Zn}^{2+}$ 的结合比率为 $1: 1$, 但是 $\mathrm{Cd}^{2+}$ 也对其表现出苂光增强作用，对锌离子的识别有一 定的干扰, 细胞实验表明探针 $\mathbf{1 6}$ 可以用于细胞内 $\mathrm{Zn}^{2+}$ 的显像.

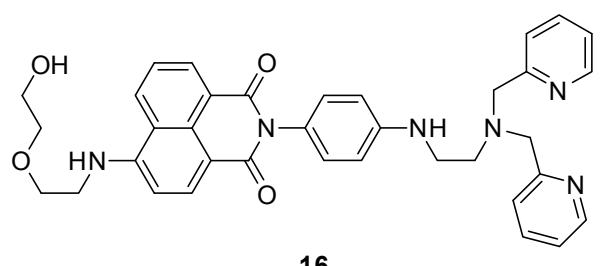

2010 年Yoon 等 ${ }^{[30]}$ 以荎酰亚胺为苂光团, 酰胺-DPA 为识别基团设计合成了 $\mathrm{Zn}^{2+}$ 荧光探针 17. 有趣的是, 研 究发现探针 17 与 $\mathrm{Zn}^{2+}$ 的结合模式和其它二价金属离子 有很大区别: 17 在水相中以亚氨酸的形式与 $\mathrm{Zn}^{2+}$ 结合, 却以酰胺的形式同其它二价金属离子结合，且亲和力远 远小于与 $\mathrm{Zn}^{2+}$ 的结合(Scheme 1). 探针 17 与 $\mathrm{Zn}^{2+}$ 结合 后，因为亚氨酸结构增长了荟酰亚胺荧光团的共轭链 
(17b)使其最大发射波长从 $483 \mathrm{~nm}$ 红移至 $514 \mathrm{~nm}$, 并且 荧光增强 22 倍(表 1). 另外值得一提的是, 17 在与 $\mathrm{Cd}^{2+}$ 结合后荧光增强 21 倍, 但其苂光波长却从 $483 \mathrm{~nm}$ 蓝移 到 $446 \mathrm{~nm}$, 因此可以利用探针 17 荧光光谱信号变化的 不同方便地区分和检测 $\mathrm{Zn}^{2+}$ 和 $\mathrm{Cd}^{2+}$, 生物利用价值大 大提高.

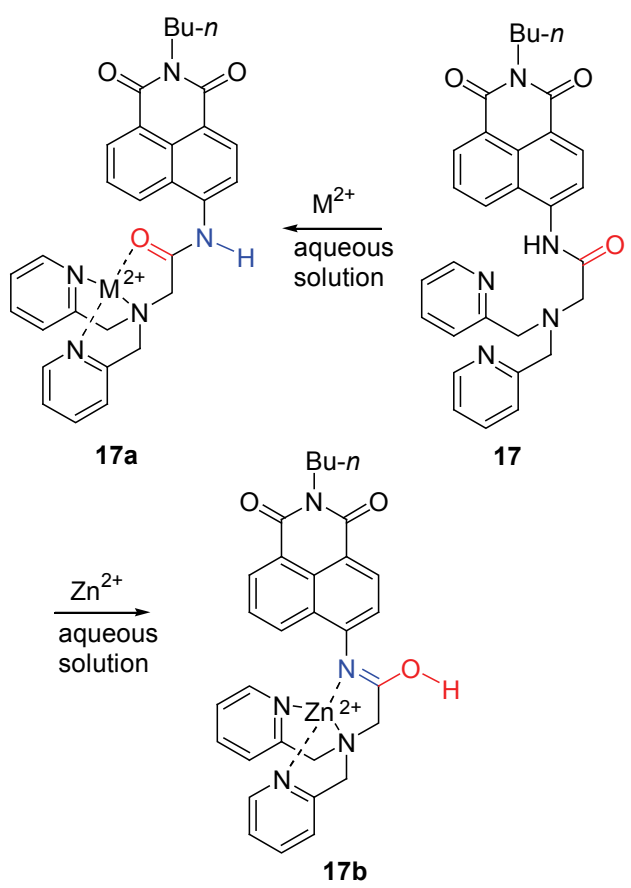

Scheme 1

\section{6 苯并唑类}

2008 年 Wang 等 ${ }^{[31]}$ 报道了以 4-氨基-7-硝基苯并二 唑(NBD)为荧光团, DPEA 和 DPA 为识别基团的 $\mathrm{Zn}^{2+}$ 苂 光探针 18 和 19. 未结合 $\mathrm{Zn}^{2+}$ 前, 探针 18 苂光强度很弱, 而 19 却表现出较强的苂光信号, 加入 $\mathrm{Zn}^{2+}$ 后探针 18 荧 光增强 25 倍, 与 $\mathrm{Zn}^{2+}$ 的结合比率为 $1: 1$, 解离常数 $K_{\mathrm{d}}$ 为 $4.6 \mu \mathrm{mol} / \mathrm{L}$, 相同条件下, 探针 19 则几乎观察不到苂 光变化, 这表明探针 18 结构中 $\mathrm{N}^{1}$ 原子在 PET 作用过程 中可能发挥着至关重要的作用(18a, Eq. 2), 由此可见, 识别基团中微小的变化可引起探针性能很大的改变. 探 针 18 具有有较好的水溶性, 荧光强度变化与 $\mathrm{Zn}^{2+}$ 浓度
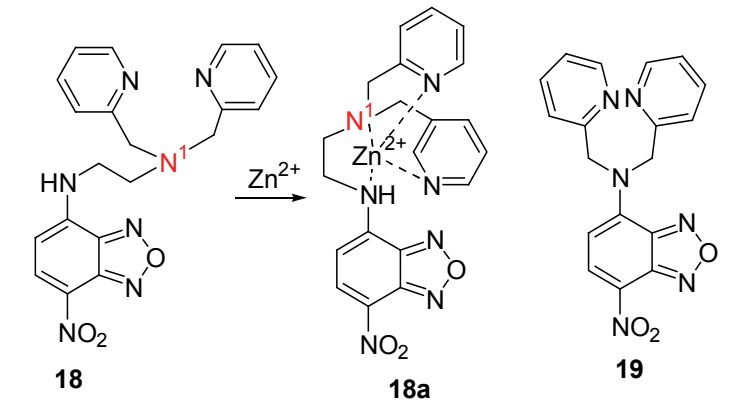

(2)

Chin. J. Org. Chem. 2013, 33, 1655 1667

(C) 2013 Chinese Chemical Society \& SIOC, CAS

http://sioc-journal.cn/

1659
成线性关系，可用于定量检测 $\mathrm{Zn}^{2+}$.

2011 年 Chuburu 等 ${ }^{[32]}$ 报道了一个以苯并咪唑为荧 光团的 $\mathrm{Zn}^{2+}$ 荧光探针 20 . 探针 $\mathbf{2 0}$ 是以四氮杂环十四烷 为识别基团, 可选择性识别 $\mathrm{Zn}^{2+}$, 由于其在水溶液中与 $\mathrm{H}^{+}$结合存在多重平衡, 探针 20 在酸性介质中无荧光, 只有在 $\mathrm{pH}>8$ 条件下才发射苂光, $\mathrm{Cu}^{2+}$ 的存在可导致其 荧光完全淬灭. 近期 Fukuzumi 等 ${ }^{[33]}$ 报道了一个在苯并 恶唑环上分别连接 DPA 和 2-羟基荟结构作为 $\mathrm{Zn}^{2+}$ 识别 基团，构建了探针 21. 该化合物结合 $\mathrm{Zn}^{2+}$ 后，水溶液由 无色转变成黄色, 荧光增强 44 倍, 探针 21 结构中羟基 的去质子化以及 DPA 氮原子的孤对电子参与金属离子 螯合从而抑制 PET 过程, 是 $\mathrm{Zn}^{2+}$ 诱导其荧光增强的原 因. 探针 21 的锌离子选择性好, $\mathrm{pH}$ 适用范围广, $\mathrm{pH}$ 3 10 范围内探针 21 的 $\mathrm{Zn}^{2+}$ 苂光检测能力不受影响(表 1), 它甚至可以对调亡细胞释放 $\mathrm{Zn}^{2+}$ 的过程进行可视化监 测.



20

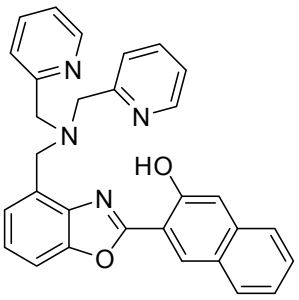

21

\section{7 亚氨二乙酸类}

亚氨二乙酸类锌离子荧光探针一般都具有一个相 类似的识别基团: BAPTA [bis(o-aminophenoxy)ethane$N, N, N^{\prime}, N^{\prime}$-tetraacetic acid, 二(邻-氨基苯氧基)乙烷- $N, N$, $N^{\prime}, N^{\prime}$-四乙酸]. Gee 等 ${ }^{[34 ~ 36]}$ 报道了通过对 BAPTA 结构修 饰得到系列 $\mathrm{Zn}^{2+}$ 苂光分子探针(22 27), 主要是去除一 个或更多个 BAPTA 上的螯合基团，使探针能够保持对 锌离子的良好亲和力, 同时降低对 $\mathrm{Ca}^{2+}$ 的结合能力. 探 针 22 在未结合 $\mathrm{Zn}^{2+}$ 前基本无荧光,一旦加入 100 $\mu \mathrm{mol} / \mathrm{L} \mathrm{Zn^{2+ }}$ 后, 其荧光强度增加 200 倍，探针 23 和 25 在相同实验条件下荧光强度分别增加 100 和 150 倍，而 探针 24 在 $\mathrm{Zn}^{2+}$ 足量条件下, 荧光强度仅提高 12 倍. 具 有更高亲和力的探针 26 游离时不发荧光, 加入 100 $\mathrm{nmol} / \mathrm{L}$ 左右 $\mathrm{Zn}^{2+}$ 后, 荧光强度增加几百倍, 探针 $\mathbf{2 7}$ 与 $\mathrm{Zn}^{2+}$ 结合后表现出 75 倍的苂光增强, 神经元细胞实验 显示, 探针 27 可有效定位和检测线粒体中游离的 $\mathrm{Zn}^{2+}$. 2003 年 Gunnlaugsson 等 ${ }^{\left[{ }^{[7]}\right.}$ 报道了一个以䒬酰亚胺为苂 光团, 芳香亚氨二乙酸为识别基团, 具有良好 $\mathrm{pH}$ 稳定 性和水溶性的荧光探针 28 , 在水溶液中加入 $\mathrm{Zn}^{2+}$ 后, 其 苂光强度增加 53 倍, 在金属离子竞争选择性方面, 探针 28 对 $\mathrm{Zn}^{2+}$ 的亲和力和选择性远超 $\mathrm{Ca}^{2+}, \mathrm{Mg}^{2+}$ 等离子. 
2008 年 Katerinopoulos 等 ${ }^{[38]}$ 报道了一个红光发射、锌离 子亲和力在纳摩尔范围的比率型 $\mathrm{Zn}^{2+}$ 苂光分子探针 29 . 其与 $\mathrm{Zn}^{2+}$ 螯合后发射光谱从 $590 \mathrm{~nm}$ 蓝移至 $564 \mathrm{~nm}$, 激 发光谱则由 $553 \mathrm{~nm}$ 蓝移至 $543 \mathrm{~nm}$, 结合 $\mathrm{Zn}^{2+}$ 的解离常 数达到了 $4.0 \mathrm{nmol} / \mathrm{L}$.

\section{8 近红外染料类}

近红外苂光分子探针的发射波长一般在 $650 \sim 900$ $\mathrm{nm}$ 范围, 具有较小的辐射能, 可避免对细胞和生物活 体样本的损伤, 能渗透到更深的活体细胞中甚至实现在 动物及人体身上检测目标物, 而且在该波长范围内生物
分子自身荧光较弱，可避免背景干扰而获得较高的分析 灵敏度，近红外菼光分子探针的这些优点都是紫外可见 荧光分子探针无法具备的.

碳菁染料(Cyanine dyes)是近红外菼光染料的一种, 目前利用 Cyanine dyes 报道的 $\mathrm{Zn}^{2+}$ 苂光探针较多，是一 个研究热点. 2007 年, 吴朝阳等 ${ }^{[39]}$ 报道了以碳菁染料 IR-780 (IR 是 Infrared 的缩写, 780 表示该染料的最大吸 收波长为 $780 \mathrm{~nm}$ )为苂光团, TAEA [三-(2-氨乙基)胺]为 识别基团的近红外 $\mathrm{Zn}^{2+}$ 苂光探针 $\mathbf{3 0}$. 探针 30 的激发和 发射波长分别位于 683 和 $750 \mathrm{~nm}, K_{\mathrm{d}}$ 达到 $1 \mathrm{nmol} / \mathrm{L}$. 然<smiles>COC(=O)CN(CC(=O)O)c1ccc(-c2c3cc(F)c(=O)cc-3oc3cc(O)c(F)cc23)cc1OC</smiles>

22<smiles></smiles><smiles>CCN1C(=O)c2cccc3c(NCc4ccc(C(CC(N)=O)CC(N)=O)cc4)ccc(c23)C1=O</smiles>

28<smiles>COc1cc(C2=c3cc4c5c(c3Oc3c2cc2c6c3CCCN6CCC2)CCC[N+]=5CCC4)ccc1N(CC(=O)O)CC(=O)O[Na]</smiles>

24<smiles>COC(=O)c1c(-c2c3cc(F)c(=O)cc-3oc3cc(O)c(O)cc23)ccc(C(=O)Nc2ccc(N(CC(C)=O)CC(C)=O)c(OC)c2)c1OC</smiles>

25<smiles></smiles><smiles>COc1cc2cc3c(oc2cc1N(CC(C)=O)CC(C)=O)c(C#N)c(=N)n1c2ccccc2nc31</smiles>

29<smiles>CCCN1C(/C=C/C2=C(N(Cc3ccccn3)Cc3ccccn3)C(/C=C/C3N(CCC)c4ccccc4C3(C)C)C[C@@H](C)C2)=C(C)C(C)(C)c2ccccc21</smiles><smiles>CC1(C)C(/C=C/C2=C(NCCN(Cc3ccccn3)Cc3ccccn3)C(/C=C/C3N(CCCCS(=O)(=O)O)c4ccccc4C3(C)C)CCC2)=[N+](CCCCS(=O)(=O)[O-])c2ccccc21</smiles><smiles>CCCN1c2ccccc2C(C)(C)C1/C=C/C1CCCC(/C=C/C2=[N+](CCC)c3ccccc3C2(C)C)=C1NCc1cccc(CN(Cc2cccnc2)Cc2ccccn2)n1</smiles> 
而, 由于脂肪链含氮基团 TAEA 的配位金属离子能力较 弱, 只有碱金属或碱土金属对探针检测 $\mathrm{Zn}^{2+}$ 没有明显 的干扰, 二价的 $\mathrm{Co}^{2+}$ 和 $\mathrm{Ni}^{2+}$ 对探针 $\mathbf{3 0}$ 可产生荧光加强, $\mathrm{Mn}^{2+}, \mathrm{Fe}^{3+}$ 和 $\mathrm{Cu}^{2+}$ 等离子的存在会引起探针荧光淬灭, 这在一定程度上限制了其在生物学上的应用.

2006 年 Tang ${ }^{[40]}$ 和 Nagano 等 ${ }^{[41]}$ 分别报道了以碳菁 染料 IR-780、IR-783 为荧光团, DPA 和 DPEA 为识别基 团的近红外 $\mathrm{Zn}^{2+}$ 荧光探针 31 和 32. 探针 31 的荧光波长 位于 $780 \mathrm{~nm}$, 与 $\mathrm{Zn}^{2+}$ 以 $1: 1$ 的比率结合, 稳定后荧光 增强 20 倍, 其可用于巨噬细胞内的 $\mathrm{Zn}^{2+}$ 苂光成像. 探 针 32 是一个比率型 $\mathrm{Zn}^{2+}$ 荧光探针, 在 HEPES 缓冲溶液 中, 结合 $\mathrm{Zn}^{2+}$ 后, 吸收波长红移 $44 \mathrm{~nm}$, 最大发射波长 则红移到 $780 \mathrm{~nm}$, 探针 32 对 $\mathrm{Zn}^{2+}$ 选择性较好, 但有意 思的是, 在溶液中加入 20 倍量的 $\mathrm{Co}^{2+}$ 时, 探针的吸收 波长红移 $39 \mathrm{~nm}$, 荧光强度也增加, 另外, 加入 $\mathrm{Cu}^{2+}$ 则 会导致探针 32 的分解.

2012 年 Yoon 等 ${ }^{[2]}$ 报道以 IR-780 为荧光团的近红 外 $\mathrm{Zn}^{2+}$ 苂光探针 33. 探针 33 以三吡定氨衍生物作为识 别基团, 向溶液中加入 $\mathrm{Zn}^{2+}$ 后, 可以观察到溶液由蓝色 转变成粉红色, 并伴随着最大发射波长从 $730 \mathrm{~nm}$ 蓝移 至 $590 \mathrm{~nm}$. 该探针对 $\mathrm{Zn}^{2+}$ 表现出良好的亲和性, $1: 1$ 比 率结合, $33 / \mathrm{Zn}^{2+}$ 配合物的解离常数达到了 $1.2 \mathrm{nmol} / \mathrm{L}$, 亲和力远远比 DPA 系列探针好, 吸收光谱强度 $I_{510 \mathrm{~nm}} /$ $I_{670 \mathrm{~nm}}$ 的比值与 $\mathrm{Zn}^{2+}$ 浓度成线性关系, 探针 33 已运用到 $\mathrm{C} 2 \mathrm{C} 12$ 和 NIH3T3 细胞甚至斑马鱼神经细胞中检测 $\mathrm{Zn}^{2+}$, 选择性和灵敏度良好.

以吩噁嗪为母体的化合物, 构成了众多的染料, 并 且具有作为药物和功能材料的应用价值. 2011 年 $\mathrm{Lu}$ 等 ${ }^{[43]}$ 以苯并吩噁嗪为苂光团, DPEA 作为识别基团, 成 功合成了一个具有良好水溶性和膜透性的近红外 $\mathrm{Zn}^{2+}$ 苂光探针 34, 磷酸缓冲溶液中探针 34 在 $582 \mathrm{~nm}$ 和 623 $\mathrm{nm}$ 处有最大吸收峰, 加入 $\mathrm{Zn}^{2+}$ 后, $582 \mathrm{~nm}$ 吸收峰发生 微弱变化, $623 \mathrm{~nm}$ 吸收峰随着 $\mathrm{Zn}^{2+}$ 浓度的增加逐渐降 低, 发射光谱在 $656 \mathrm{~nm}$ 处有最大峰值, 且该峰强度几乎 与加入的 $\mathrm{Zn}^{2+}$ 浓度成正相关, 生物应用研究表明探针 34 具有细胞膜透性, 且没有明显的细胞毒性, 是一个颇 有前途的可以应用在水溶液和活细胞中检测 $\mathrm{Zn}^{2+}$ 的荧 光探针.

2012 年 $\mathrm{Lu}$ 等 ${ }^{[44]}$ 利用吩噁嗪母核为荧光团, 甲基取 代的 DPEA 为识别基团, 报道了近红外 $\mathrm{Zn}^{2+}$ 苂光探针 35, 与探针 34 相比, 35 吩噁嗪母核中缺少骈苯结构, 其 主要目的可能是使水溶液中不存在离子平衡, 能够相应 地提高探针的 $\mathrm{pH}$ 稳定性, 实验表明探针 35 在 $\mathrm{pH} 6.0$ 10.0 范围内苂光无明显变化(表 1), 稳定性优于探针 34 . 游离的探针 35 最大吸收峰出现在 $657 \mathrm{~nm}$, 加入 $\mathrm{Zn}^{2+}$ 后, 蓝移 $10 \mathrm{~nm}$, 同时发现用 $650 \mathrm{~nm}$ 波长光照射未结合 $\mathrm{Zn}^{2+}$ 时的探针 35, 发现其表现微弱的苂光, 结合 $\mathrm{Zn}^{2+}$ 后 $677 \mathrm{~nm}$ 处苂光强度逐渐增加, 4 倍量时该值达到稳定, 探针 35 已成功实现了 $\mathrm{KB}$ 细胞中 $\mathrm{Zn}^{2+}$ 的检测.<smiles></smiles>

表 1 基于 PET 作用机理的 $\mathrm{Zn}^{2+}$ 苂光分子探针的光化学性质

Table 1 The spectroscopic properties of $\mathrm{Zn}^{2+}$ fluorescent probes based on PET

\begin{tabular}{cllcll}
\hline 化合物 & \multicolumn{1}{c}{$\lambda_{\max , \mathrm{abs}} / \mathrm{nm}$} & $\lambda_{\max , \mathrm{em}} / \mathrm{nm}$ & 苂光增强倍数 & \multicolumn{1}{c}{$K_{\mathrm{d}}$} & $\mathrm{pH}$ 适用范围 \\
\hline $\mathbf{1}$ & $240 / 270^{a}$ & $425 / 438^{b}$ & 14.3 & $(0.45 \pm 0.02) \mathrm{fmol} / \mathrm{L}$ & 7.4 (HEPES) \\
$\mathbf{2}$ & $302 / 360$ & $532^{d}$ & 3.7 & $(1.8 \pm 0.1) \mathrm{pmol} / \mathrm{L}$ & $6.0 \sim 10.0$ (HEPES) \\
$\mathbf{3}$ & $238 / 252,350$ & $500 / 500$ & 10.6 & $(58.5 \pm 5.4) \mathrm{mmol} / \mathrm{L}$ & $6.5 \sim 8.0$ (HEPES) \\
$\mathbf{4}$ & $492 / 492$ & $514 / 514$ & 17 & $0.78 \mathrm{nmol} / \mathrm{L}$ & 7.5 (HEPES) \\
$\mathbf{5}$ & $492 / 492$ & $514 / 514$ & 51 & $2.7 \mathrm{nmol} / \mathrm{L}$ & 7.5 (HEPES) \\
$\mathbf{6}$ & $515 / 507$ & $525 / 525$ & 2.3 & $(0.7 \pm 0.1) \mathrm{nmol} / \mathrm{L}$ & $5.5 \sim 8.4$ (PIPES) \\
$\mathbf{7}$ & $498 / 490$ & $515 / 515$ & 3.7 & $(0.5 \pm 0.1) \mathrm{nmol} / \mathrm{L}$ & $5.5 \sim 9.4$ (PIPES) \\
$\mathbf{8}$ & $505 / 498$ & $524 / 524$ & 32.5 & $(48 \pm 3) \mu \mathrm{mol} / \mathrm{L}$ & 7.0 (PIPES) \\
$\mathbf{9}$ & $499 / 489$ & $520 / 518$ & 140 & $(41 \pm 3) \mu \mathrm{mol} / \mathrm{L}$ & 7.0 (PIPES) \\
$\mathbf{1 0}$ & $517 / 503$ & $532 / 523$ & 13.5 & $0.38 \mathrm{nmol} / \mathrm{L}$ & 7.0 (PIPES) \\
$\mathbf{1 1}$ & $345 / 345$ & $446 / 446$ & 4.4 & $1 \mu \mathrm{mol} / \mathrm{L}$ & 7.0 (HEPES) \\
\hline
\end{tabular}




\begin{tabular}{|c|c|c|c|c|c|}
\hline 化合物 & $\lambda_{\max , \text { abs }} / \mathrm{nm}$ & $\lambda_{\max , \mathrm{em}} / \mathrm{nm}$ & 苂光增强倍数 & $K_{\mathrm{d}}$ & pH 适用范围 \\
\hline 12 & $350 / 350$ & $650 / 650$ & 23 & $0.5 \mu \mathrm{mol} / \mathrm{L}(\mathrm{MeOH})$ & $4.0 \sim 11.0(\mathrm{MeOH})$ \\
\hline 13 & $416 / 407$ & $483 / 457$ & Turn on ${ }^{e}$ & $(0.95 \pm 0.35) \mu \mathrm{mol} / \mathrm{L}$ & $3.6 \sim 7.4$ (乙醇/水) \\
\hline 14 & 499/499 & $509 / 509$ & 19.3 & $0.24 \mu \mathrm{mol} / \mathrm{L}$ & $5.0 \sim 7.0$ (HEPES) \\
\hline 15 & $491 / 491$ & $509 / 509$ & 11.1 & $(1.0 \pm 0.1) \mathrm{nmol} / \mathrm{L}$ & $3.0 \sim 10.0(\mathrm{PBS})$ \\
\hline 16 & $449 / 449$ & $550 / 550$ & 6 & $(0.62 \pm 0.1) \mathrm{nmol} / \mathrm{L}$ & $3.6 \sim 8.0$ (乙醇/水) \\
\hline 17 & $360 / 360$ & $483 / 514$ & 22 & $5.7 \mathrm{nmol} / \mathrm{L}$ & $6.3 \sim 12.8$ (乙腈/水) \\
\hline 18 & $470 / 470$ & $550 / 550$ & 25 & $4.6 \mu \mathrm{mol} / \mathrm{L}$ & 7.3 (PBS) \\
\hline 20 & $207 / 207$ & $304 / 304$ & 12 & $15 \mathrm{nmol} / \mathrm{L}$ & $>8.0(\mathrm{CAPS})$ \\
\hline 21 & $318 / 290$ & $550 / 542$ & 44 & $12 \mathrm{pmol} / \mathrm{L}$ & $3.0 \sim 10.0$ (PIPES) \\
\hline 22 & $491 / 491$ & $520 / 520$ & 200 & $7.8 \mu \mathrm{mol} / \mathrm{L}$ & $6.0 \sim 9.0($ MOPS $)$ \\
\hline 23 & $548 / 548$ & $589 / 589$ & 100 & $23.0 \mu \mathrm{mol} / \mathrm{L}$ & $6.0 \sim 9.0$ (MOPS) \\
\hline 24 & $575 / 575$ & $604 / 604$ & 12 & $11.0 \mu \mathrm{mol} / \mathrm{L}$ & $6.0 \sim 9.0(\mathrm{MOPS})$ \\
\hline 25 & $492 / 492$ & $521 / 521$ & 150 & $2.1 \mu \mathrm{mol} / \mathrm{L}$ & $6.0 \sim 9.0(\mathrm{MOPS})$ \\
\hline 26 & $491 / 491$ & $520 / 520$ & 几百倍 & $15.0 \mathrm{nmol} / \mathrm{L}$ & $6.0 \sim 9.0(\mathrm{MOPS})$ \\
\hline 27 & $488 / 488$ & $515 / 515$ & 75 & $(15.0 \pm 2.0) \mathrm{nmol} / \mathrm{L}$ & $6.0 \sim 9.0(\mathrm{MOPS})$ \\
\hline 28 & $442 / 442$ & $550 / 550$ & 52.5 & $80.0 \mathrm{nmol} / \mathrm{L}$ & $5.0 \sim 12.0$ (HEPES) \\
\hline 29 & $553 / 543$ & $590 / 564$ & Turn on & $4.0 \mathrm{nmol} / \mathrm{L}$ & 7.0 (HEPES) \\
\hline 30 & $683 / 683$ & $750 / 750$ & Turn on & $1.0 \mathrm{nmol} / \mathrm{L}$ & 7.4 (HEPES) \\
\hline 31 & $730 / 730$ & $780 / 780$ & 20 & $63 \mathrm{nmol} / \mathrm{L}$ & $6.4 \sim 7.5$ (HEPES) \\
\hline 32 & $627 / 671$ & $758 / 765$ & Turn on & $(98 \pm 0.9) \mathrm{nmol} / \mathrm{L}$ & 7.4 (HEPES) \\
\hline 33 & $670 / 510$ & $730 / 590$ & Turn on & $1.2 \mathrm{nmol} / \mathrm{L}$ & $2.8 \sim 9.7$ (HEPES) \\
\hline 34 & $582,623 / 582$ & $656 / 656$ & 1.9 & $(73.5 \pm 9.0) \mathrm{mmol} / \mathrm{L}$ & 7.4 (PBS) \\
\hline 35 & $657 / 647$ & $/ 677$ & 7.0 & $50 \mathrm{nmol} / \mathrm{L}$ & $6.0 \sim 10.0(\mathrm{PBS})$ \\
\hline
\end{tabular}

$\bar{a}$ 前面数据为探针游离时最大吸收波长, 后面数据为探针结合 $\mathrm{Zn}^{2+}$ 后的最大吸收波长. ${ }^{b}$ 前面数据为探针游离时最大发射波长, 后面数据为探针结合 $\mathrm{Zn}^{2+}$ 后 的最大发射波长). ${ }^{c}$ 原文献中未给出探针的具体 $\mathrm{pH}$ 适用范围, $\mathrm{pH}$ 一般取为 $7.0 \sim 7.5$, 括号内为缓冲液体系. ${ }^{d}$ 探针游离时基本不发射荧光, 因此无最大发射 波长. ${ }^{e}$ 原文献中未给出具体的苂光增强倍数, “turn on” 表示探针结合 $\mathrm{Zn}^{2+}$ 后表现苂光增强.

\section{2 基于分子内电荷转移 (Intramolecular Charge Transfer, ICT)机理}

ICT 机理是荧光分子探针设计中经常被运用的另一 个机理 ${ }^{[5]}$. 典型的 ICT 荧光分子探针是在荧光团上分别 连接强推电子基和吸电子基, 构成一个强推拉电子体 系, 推电子基和吸电子基、荧光团共轭相连, 在光激发 下会产生从电子给体向电子受体的电荷转移, 当识别基 团与客体结合时, 会对苂光团的推拉电子体系产生影 响, 减弱或强化分子内电荷转移, 从而导致荧光光谱的 变化: 如果识别基团是电子供体, 则结合客体后会发生 荧光光谱的蓝移, 反之, 荧光发射光谱将发生红移(图 2). 由此看来, 通常可利用基于 ICT 机理的荧光分子探 针发射波长的移动变化设计成比率型 $\mathrm{Zn}^{2+}$ 苂光分子探 针.

在已报道的应用 ICT 机理的 $\mathrm{Zn}^{2+}$ 苂光分子探针中 是大致可分为: 苯并呋喃类、香豆素类、亚氨二乙酸类、 氟硼荧染料类、荥酰亚胺类、喹啉类等.

\section{1 苯并呋喃类}

2002 年 Nagano 等 ${ }^{[45]}$ 报道了两个以苯并呋喃为荧光 团的比率计量型 $\mathrm{Zn}^{2+}$ 苂光探针 36 和 37. 实验表明探针

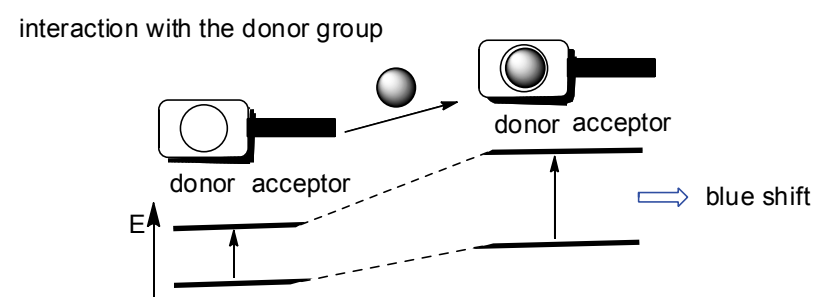

interaction with the acceptor group

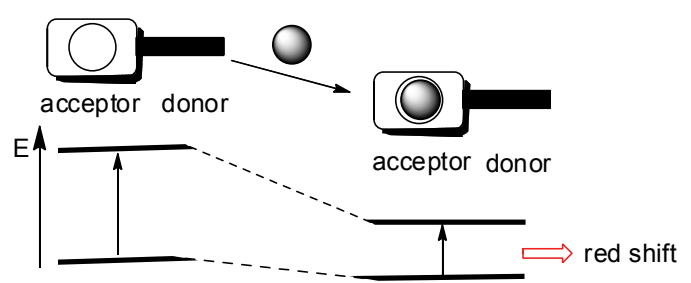

图 2 基于 ICT 机理作用示意图

Figure 2 Schematic illustration of the mechanism based on ICT 37 的水溶性及苂光性质好, 更适合生物体系中 $\mathrm{Zn}^{2+}$ 检 测. 随着 $\mathrm{Zn}^{2+}$ 的增加，探针 37 的最大激发波长从 365 $\mathrm{nm}$ 蓝移到 $335 \mathrm{~nm}$, 荧光强度比值 $\left(I_{335} \mathrm{~nm} / I_{365} \mathrm{~nm}\right)$ 不断增 大, 测定该比值可以实现对 $\mathrm{Zn}^{2+}$ 浓度的定量检测. 探针 37 已成功运用到生物活体细胞内 $\mathrm{Zn}^{2+}$ 的显像. $\mathrm{Cd}^{2+}$ 对该 探针的检测有一定干扰, 另外 $\mathrm{Cu}^{2+}, \mathrm{Co}^{2+}$ 与探针 37 能形 成配合物并使其荧光淬灭. 
<smiles>COc1cc2cc(-c3ccc(C(=O)O)cc3)oc2cc1NCCN(Cc1ccccn1)Cc1ccccn1</smiles><smiles>COc1cc2cc(-c3ncc(C(=O)O)o3)oc2cc1NCCN(Cc1ccccn1)Cc1ccccn1</smiles>

\section{2 香豆素类}

2004 年 Bruckner 等 ${ }^{[46]}$ 以 7-氨基香豆素为荧光团报 道了一个比率型 $\mathrm{Zn}^{2+}$ 荧光探针 38 , 在甲醇溶液中加入 $\mathrm{Zn}^{2+}$ 后其最大发射波长从 $400 \mathrm{~nm}$ 红移至 $431 \mathrm{~nm}$, 最大 吸收波长从 $484 \mathrm{~nm}$ 红移至 $505 \mathrm{~nm}$. 探针 38 结构中内酯 氧原子参与了 $\mathrm{Zn}^{2+}$ 配位 $(\mathbf{3 8 a})$, 使探针发生 ICT 过程, $\mathrm{Cu}^{2+}$ 和 $\mathrm{Ni}^{2+}$ 对其有苂光淬灭作用, $\mathrm{Cd}^{2+}$ 的存在会对检测 $\mathrm{Zn}^{2+}$ 产生一定干扰.

2007 年 Nagano 等 ${ }^{[47]}$ 报道了一个以 7 氨基-2-亚氨基 香豆素衍生物为荧光团的比率型 $\mathrm{Zn}^{2+}$ 荧光探针 39. 游 离的探针 39 激发波长和发射波长分别为 513 和 $543 \mathrm{~nm}$, 荧光量子产率 $\Phi$ 为 0.8 , 发出很强的绿色荧光, 加入 $\mathrm{Zn}^{2+}$ 后, 荧光颜色由开始的绿色变成黄色, 发射光谱峰 从 $543 \mathrm{~nm}$ 蓝移至 $524,513 \mathrm{~nm}$ 波长光激发的荧光光谱中 心在 $558 \mathrm{~nm}, I_{558 \mathrm{~nm}} / I_{543 \mathrm{~nm}}$ 的比值与 $\mathrm{Zn}^{2+}$ 浓度成线性关 系. 由于 2 号位亚胺结构的存在, 在碱性环境中其发生 苂光淬灭, 因此只能应用在酸性或中性条件下, 在生理 条件下, 探针 39 可以用来检测大鼠和海马细胞中 $\mathrm{Zn}^{2+}$ 浓度的变化.

\section{3 亚氨二乙酸类}

另外, Gee 等 ${ }^{[34,35]}$ 通过对 BAPTA 的结构修饰还设计 合成了两个基于 ICT 作用机理的 $\mathrm{Zn}^{2+}$ 苂光分子探针 40 和 41. 在探针 40 的 $\mathrm{Zn}^{2+}$ 滴定过程中, 随着 $\mathrm{Zn}^{2+}$ 浓度的 增加激发波长从 $378 \mathrm{~nm}$ 蓝移到 $330 \mathrm{~nm}$, 同样条件下, 41 的苂光波长从 $480 \mathrm{~nm}$ 蓝移至 $395 \mathrm{~nm}$. 在细胞分析实验 中, 两者对 $1 \sim 2 \mathrm{mmol} / \mathrm{L}$ 的 $\mathrm{Ca}^{2+}, \mathrm{Mg}^{2+}$ 无响应, 同时与 $\mathrm{Zn}^{2+}$ 的结合常数达到 $300 \sim 400 \mathrm{nmol} / \mathrm{L}$. 总之, 亚氨乙酸 类 $\mathrm{Zn}^{2+}$ 苂光探针具有温和的 $\mathrm{Zn}^{2+}$ 亲和能力, 且表现出 对 $\mathrm{Zn}^{2+}$ 的选择性超过 $\mathrm{Ca}^{2+}, \mathrm{Mg}^{2+}$ 等离子.<smiles>O=c1oc2c3c4c(cc2cc1CN(Cc1ccccn1)Cc1ccccn1)CCCN4CCC3</smiles>

38

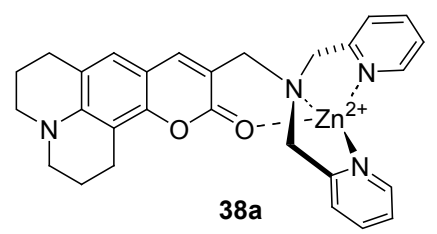<smiles>c1ccc(CN(CCN=c2oc3c4c5c(cc3cc2-c2nc3ccccc3s2)CCCN5CCC4)Cc2ccccn2)nc1</smiles>

39<smiles>COc1cc2cc(-c3ncc(C(=O)O)o3)oc2cc1N(CC(=O)O)CC(=O)O</smiles><smiles>COc1cc(-c2cc3ccc(C(=O)O[Na])cc3[nH]2)ccc1C(CC(=O)O)CC(=O)O[Na]</smiles>

\section{4 氟嗍荧(BODIPY)类}

2008 年 Akkaya 等 ${ }^{[48]}$ 以 BODIPY 为荧光团设计合成 了能高选择性检测 $\mathrm{Zn}^{2+}$ 浓度的近红外“OFF-ON”型苂光 分子探针 42. 在 BODIPY 分子中引入了六个 TEG(三乙 烯乙二醇)基团，增加了探针分子的水溶性，向探针 42 水溶液中加入 $\mathrm{Zn}^{2+}$ 后，苂光发射波长从 $730 \mathrm{~nm}$ 蓝移至 $680 \mathrm{~nm}$. 加入其他金属离子, 探针 42 的苂光变化不明 显, $\mathrm{Hg}^{2+}$ 和 $\mathrm{Cd}^{2+}$ 对其表现为荧光增强, 但变化比较微弱,



42

http://sioc-journal.cn/ 
并不会影响探针 42 在生物学上的应用.

\section{5 荎酰亚胺类}

2007 年钱旭红等 ${ }^{[49]}$ 构建了一个通过不同的 ICT 过 程区分 $\mathrm{Zn}^{2+}$ 和 $\mathrm{Cd}^{2+}$ 的分子探针 43 , 它对两种离子采用 不同的络合模式, 从而产生不同的荧光变化, 达到分别 检测 $\mathrm{Zn}^{2+} / \mathrm{Cd}^{2+}$ 的目的. $\mathrm{Cd}^{2+}$ 的存在诱导探针 43 发生 ICT 过程，导致其共轭体系的改变，荧光发射波长从 $531 \mathrm{~nm}$ 蓝移至 $487 \mathrm{~nm}$, 而当向含探针 43 的乙腈水溶液中加入 $\mathrm{Zn}^{2+}$ 后, 与菜酰亚胺相连的-NH 先脱去了质子, 因此该 氮原子对母核的给电子能力大大增强, 再与 $\mathrm{Zn}^{2+}$ 相互 作用时, 由于 ICT 的缘故, 导致探针 43 的荧光波长从 $531 \mathrm{~nm}$ 红移至 $558 \mathrm{~nm}$ (表 2). 2010 年 Nagano 等 ${ }^{[50]}$ 报道 了一个以 4-氨基-1,8- 䒬二甲酰亚胺为苂光团的 “OFF-ON”型 $\mathrm{Zn}^{2+}$ 苂光分子探针 44. 在未结合 $\mathrm{Zn}^{2+}$ 时探 针 44 发出很弱的苂光 $(\Phi=0.039), 437 \mathrm{~nm}$ 处有最大吸 收, 在 HEPES 缓冲溶液中加入一倍量的 $\mathrm{Zn}^{2+}$, 最大吸 收峰蓝移 $57 \mathrm{~nm}$, 最大发射波长位于 $380 \mathrm{~nm}$ ( $\Phi$ 增加至 0.942), 发出绿色荧光. 探针 44 对 $\mathrm{Zn}^{2+}$ 选择性较高, 但 $\mathrm{Co}^{2+}$ 和 $\mathrm{Cu}^{2+}$ 存在时荧光发生淬灭, 在生物学应用上, 探 针 44 能够用于监测 $\mathrm{HeLa}$ 细胞中 $\mathrm{Zn}^{2+}$ 的变化.
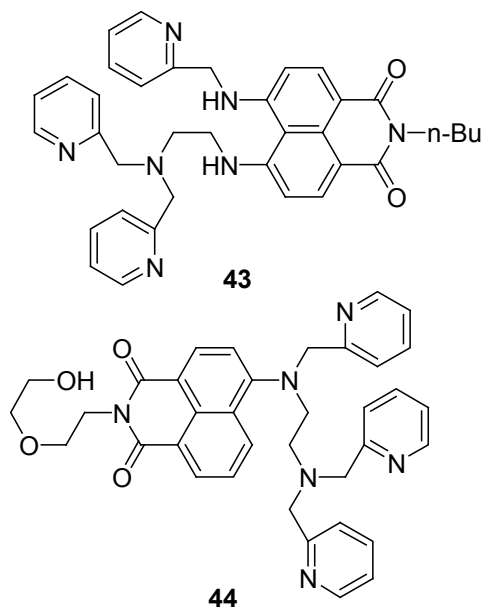

\section{6 喹啉类}

2008 年钱旭红等 ${ }^{[51]}$ 利用 8 -氨基喹啉为苂光团, 在 母核上引入亲水性良好且能提供多个金属离子结合位 点的 2-(2-羊基乙氧基)基团作为识别基团构建了 $\mathrm{Zn}^{2+}$ 苂 光探针 45. 向探针水溶液中加入 $\mathrm{Zn}^{2+}$ 后, 探针 45 苂光 量子产率增加 8 倍, 发射波长从 $440 \mathrm{~nm}$ 红移至 515 $\mathrm{nm}$ (表 2). 发生荧光光谱谱变化的原因一方面是由于喹 啉 1 位 $\mathrm{N}$ 原子与 $\mathrm{Zn}^{2+}$ 配位后发生 ICT 过程, 另一方面是 探针 45 结合 $\mathrm{Zn}^{2+}$ 后, 化学式中的酰胺结构发生去质子 化, 破坏了喹啉 $\mathrm{N}$ 原子与酰胺 $\mathrm{H}$ 原子之间的分子内氢 键, 8 位 $\mathrm{N}$ 原子在去质子化后供电子能力增强. 探针 45
能够比率识别 $\mathrm{Zn}^{2+}$, 还能用于酵母细胞中的 $\mathrm{Zn}^{2+}$ 菼光 显微成像.

2010 年彭孝军等 ${ }^{[52]}$ 同样是利用 8 -氨基喹啉为荧光 母核，而以 DPA 为识别基团设计合成了探针 46. 探针 46 螯合 $\mathrm{Zn}^{2+}$ 后的作用过程与 45 相同，也是由于 ICT 作 用和酰胺结构的去质子化达到苂光量子产率增加及苂 光波长的红移. 游离的探针 46 发射波长为 $407 \mathrm{~nm}$, 络 合 $\mathrm{Zn}^{2+}$ 后, $407 \mathrm{~nm}$ 波长峰逐渐降低, 并伴随着 $499 \mathrm{~nm}$ 出 现一个强峰, 且 $I_{499} \mathrm{~nm} / I_{407} \mathrm{~nm}$ 值与 $\mathrm{Zn}^{2+}$ 浓度成正相关. 2012 年孟祥明等 ${ }^{[53}$ 报道了两个以喹啉为荧光母核，比 率双光子显微成像型 $\mathrm{Zn}^{2+}$ 苂光分子探针 47 和 48 . 两者 因为 6 位上取代的不同, 光学性能产生了一些差别: 游 离的 47 和 48 的最大发射波长分别为 412 和 $443 \mathrm{~nm}$, 络 合 $\mathrm{Zn}^{2+}$ 后，发射波长分别红移 72 和 $81 \mathrm{~nm}$ (表 2), 苂光 量子产率分别增加 7 倍和 5 倍, 产生差别的主要原因是 探针 48 的炔基与苂光团参与更多的共轭. 双光子苂光 显像表明探针 48 活性更优，两者都可用于细胞内的 $\mathrm{Zn}^{2+}$ 苂光成像.

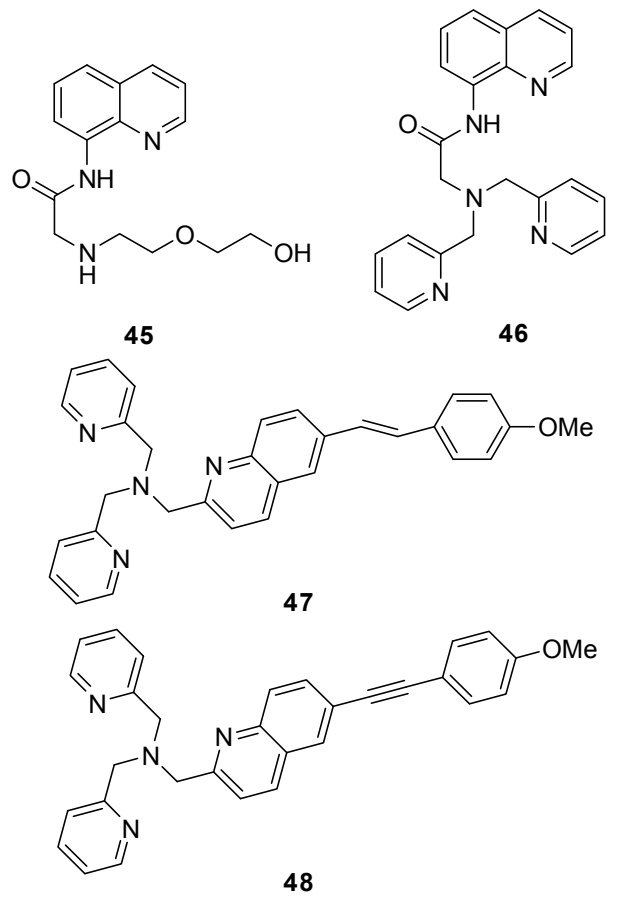

2012 年 Zeng 等 ${ }^{[54]}$ 利用 8-氨基喹啉和罗丹明 $6 \mathrm{G}$ 合 成了 $\mathrm{Zn}^{2+}$ 苂光分子探针 49. 起初认为加入 $\mathrm{Zn}^{2+}$ 后可诱 导罗丹明 $6 \mathrm{G}$ 的螺内酰胺开环产生荧光效应，结果却发 现在波长 450 700 nm 并未出现吸收峰, 另外用 480 $520 \mathrm{~nm}$ 波长光照射探针溶液, $530 \sim 650 \mathrm{~nm}$ 波长范围内 也未出现发射峰，这表明罗丹明 $6 \mathrm{G}$ 母核的螺内酰胺 $\mathrm{N}$ 原子没有参与锌离子配位，未发生开环. 探针 49 结合 $\mathrm{Zn}^{2+}$ 后, $499 \mathrm{~nm}$ 荧光峰增强 77 倍，导致荧光增强的原因 可从以下两方面来解释: (1)罗丹明母核侧链上的 3 个 $\mathrm{N}$ 
原子参与配位离子后, 发生了 ICT 过程; (2)探针 49 配位 原子与 $\mathrm{Zn}^{2+}$ 络合后形成一个刚性环结构(49a). 探针 49 在活细胞中对 $\mathrm{Zn}^{2+}$ 的检测具有很好的应用前景.

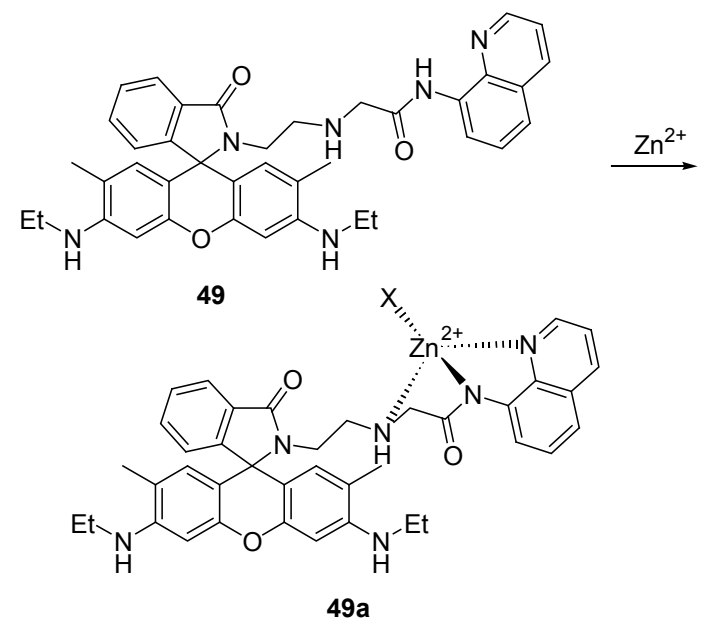

\section{3 基于苂光能量共振转移 (Fluorescence Resonance Energy Transfer, FRET)机理}

FRET 是指一个荧光体系中含有两个苂光团, 一个 充当能量供体 $\mathrm{D}$, 另一个为能量受体 $\mathrm{A}$, 在一定波长的 光激发下, 供体 $\mathrm{D}$ 产生荧光, 并通过能量耦合作用, 发 生从 D 到 $\mathrm{A}$ 的非辐射能量转移的过程 ${ }^{[5]}$ (图 3).

一般而言, 基于 ICT 或 PET 机理的比率型荧光探针 有一个重大缺陷: 探针分子在螯合响应金属离子之前与



图 3 基于 FRET 机理作用示意图

Figure 3 Schematic illustration of the mechanism based on FRET

之后激发波长相对的红移或蓝移并不会使两个峰完全 的分开, 即会有部分的重叠, 从而导致两峰较低的分辨 率以及探针无法应用到细胞内定量检测响应离子. 基于 FRET 机理的荧光探针从理论上来说可以解决该问题, 因为能量供体的发射波长在一个相对较短的范围内, 而 能量受体的发射波长在更长的范围内.

2010 年 Zhang 等 ${ }^{[56]}$ 报道了一个以苂光素为能量供 体，罗丹明为能量受体的基于 FRET 机理的 $\mathrm{Zn}^{2+}$ 苂光探 针 50. 该探针在 HEPES 缓冲液中用 $485 \mathrm{~nm}$ 波长光激发, 苂光素发射 $518 \mathrm{~nm}$ 波长苂光, $560 \mathrm{~nm}$ 波长光激发, 罗丹 明在 $585 \mathrm{~nm}$ 左右处并没有荧光峰出现, 加入 $\mathrm{Zn}^{2+}$ 后,

表 2 基于 ICT 作用机理的 $\mathrm{Zn}^{2+}$ 荧光分子探针的光化学性质

Table 2 The spectroscopic properties of $\mathrm{Zn}^{2+}$ fluorescent probes based on ICT

\begin{tabular}{clccll}
\hline 化合物 & \multicolumn{1}{c}{$\lambda_{\max , \mathrm{abs}} / \mathrm{nm}$} & $\lambda_{\max , \mathrm{em} / \mathrm{nm}}$ & 探针类型 $^{c}$ & $K_{\mathrm{d}}$ & $\mathrm{pH}$ 适用范围 \\
\hline $\mathbf{3 6}$ & $359 / 329^{a}$ & $532 / 528^{b}$ & 比率 & $0.79 \mathrm{nmol} / \mathrm{L}$ & 7.4 (HEPES) ${ }^{d}$ \\
$\mathbf{3 7}$ & $365 / 335$ & $495 / 495$ & 比率 & $2.8 \mathrm{nmol} / \mathrm{L}$ & 7.4 (HEPES) \\
$\mathbf{3 8}$ & $400 / 431$ & $483 / 505$ & 比率 & e $^{e}$ & $7.4(\mathrm{MeOH})$ \\
$\mathbf{3 9}$ & $513 / 524$ & $543 / 558$ & 比率 & $1.3 \mathrm{pmol} / \mathrm{L}$ & $3.0 \sim 9.0$ (HEPES) \\
$\mathbf{4 0}$ & $378 / 330$ & $510 / 510$ & 比率 & $3.4 \mu \mathrm{mol} / \mathrm{L}$ & $6.0 \sim 9.0$ (MOPS) \\
$\mathbf{4 1}$ & $350 / 350$ & $480 / 395$ & 比率 & $3.0 \mu \mathrm{mol} / \mathrm{L}$ & $6.0 \sim 9.0$ (MOPS) \\
$\mathbf{4 2}$ & $680 / 630$ & $726 / 680$ & Off-on & $20 \mu \mathrm{mol} / \mathrm{L}$ & 7.2 (HEPES) \\
$\mathbf{4 3}$ & $460 / 492$ & $531 / 558$ & 比率 & $16.5 \mu \mathrm{mol} / \mathrm{L}$ & $6.8 \sim 10.0$ (HEPES) \\
$\mathbf{4 4}$ & $437 / 380$ & $523 / 507$ & Off-on & $1.1 \mathrm{nmol} / \mathrm{L}$ & $3.0 \sim 9.0$ (HEPES) \\
$\mathbf{4 5}$ & $305 / 344$ & $440 / 515$ & 比率 & $6.7 \mu \mathrm{mol} / \mathrm{L}$ & 7.2 (甲醇/水) \\
$\mathbf{4 6}$ & $235,311 / 262,363$ & $407 / 499$ & 比率 & $2.0 \mathrm{nmol} / \mathrm{L}$ & 7.4 (MeOH ) \\
$\mathbf{4 7}$ & $350 / 350$ & $412 / 493$ & 比率 & $0.58 \mathrm{nmol} / \mathrm{L}$ & 7.4 (乙醇/水) \\
$\mathbf{4 8}$ & $416 / 407$ & 比率 & $0.45 \mathrm{nmol} / \mathrm{L}$ & 7.4 (HEPES) \\
$\mathbf{4 9}$ & $237,303 / 256,362$ & $443 / 515$ & Off-on & $34.5 \mu \mathrm{mol} / \mathrm{L}$ & $5.5 \sim 9.0$ (乙腈/水) \\
\hline
\end{tabular}

a 前面数据为探针游离时最大吸收波长, 后面数据为探针结合 $\mathrm{Zn}^{2+}$ 后的最大吸收波长. ${ }^{b}$ 前面数据为探针游离时最大发射波长, 后面数据为探针结合 $\mathrm{Zn}^{2+}$ 后 的最大发射波长. “基于 ICT 作用机理的一般是比率型探针, 若变化的两波长不成比例一般为 “off-on” 型. ${ }^{d}$ 原文献中未给出探针的具体 $\mathrm{pH}$ 适用范围, $\mathrm{pH}$ 一般取为 $7.0 \sim 7.5$, 括号内为缓冲液体系. ${ }^{e}$ 原文献中未给出具体的 $K_{\mathrm{d}}$ 数值. 
荧光素 $518 \mathrm{~nm}$ 苂光峰降低, 而能量受体罗丹明在 590 $\mathrm{nm}$ 处出现一个强峰, 且 $I_{590 \mathrm{~nm}} / I_{518} \mathrm{~nm}$ 与锌离子浓度 $\left(2.0 \times 10^{-7} \sim 2.0 \times 10^{-5}\right)$ 范围成良好线性关系, 检测限和 定量限分别达到了 $4.0 \times 10^{-8}, 3.0 \times 10^{-7} \mathrm{~mol} / \mathrm{L}$, 显示了 探针 50 比率计量锌离子浓度的巨大优势. 锌离子的选 择性和其他金属离子的干扰试验证明探针 $\mathbf{5 0}$ 对 $\mathrm{Zn}^{2+}$ 选 择性高, 灵敏性强, 能够可逆、快速响应 $\mathrm{Zn}^{2+}$ 的变化, 更重要的是探针 50 解决了上述系列 $\mathrm{Zn}^{2+}$ 荧光探针普遍 存在的 $\mathrm{Cd}^{2+}$ 干扰问题. 但是当 $\mathrm{Hg}^{2+}$ 浓度超过 $20 \mu \mathrm{mol} / \mathrm{L}$ 时对探针检测 $\mathrm{Zn}^{2+}$ 有干扰, 这可能是探针结构中含有 对 $\mathrm{Hg}^{2+}$ 良好亲和力的 $\mathrm{S}$ 原子的缘故, 但是 $20 \mu \mathrm{mol} / \mathrm{L}$ 远 远超过探针对 $\mathrm{Zn}^{2+}$ 的检测浓度, 所以这并不会降低其 在生物学应用上的价值. 细胞实验表明探针 $\mathbf{5 0}$ 能够高 分辨地监测细胞内的 $\mathrm{Zn}^{2+}$.
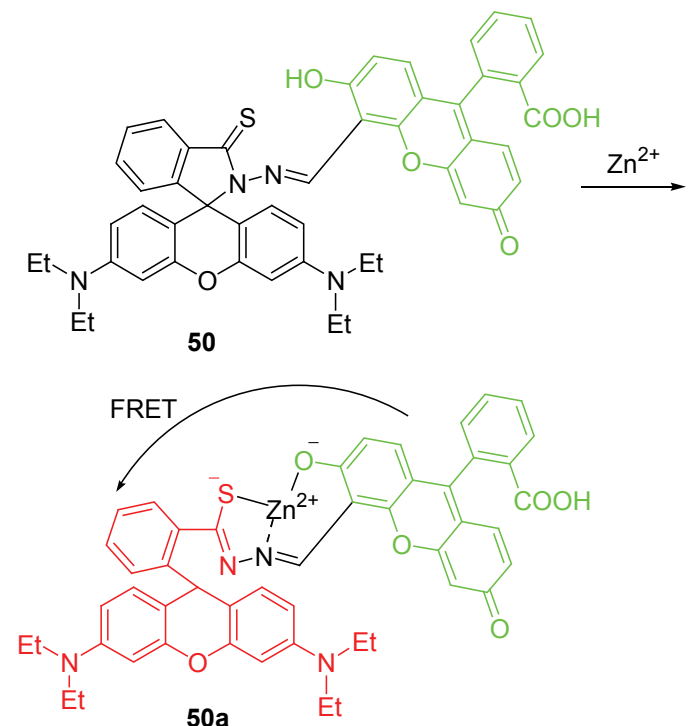

\section{4 总结与展望}

除了利用上述三种荧光作用机理设计锌离子荧光 分子探针外, PET 和 ICT 共同作用的 $\mathrm{Zn}^{2+}$ 荧光分子探 针 ${ }^{[57 ~ 59]}$, PET 和 FRET 相互协调作用的 $\mathrm{Zn}^{2+}$ 荧光分子探 针 ${ }^{[60]}$, 激发态分子内质子转移(ESIPT; excited-state intramolecular proton transfer) 作用的 $\mathrm{Zn}^{2+}$ 荧光分子探 针 ${ }^{[61 ~ 63]}$ 等都有报道. 综上所述, 近年来 $\mathrm{Zn}^{2+}$ 荧光分子探 针的研究已经取得了很大的进展, 部分探针分子甚至能 够用于生物体和细胞内的 $\mathrm{Zn}^{2+}$ 检测, 但对活体内 $\mathrm{Zn}^{2+}$ 的定量检测和分析等方面的新型荧光分子探针还有待 发展; 另外, 由于锌离子的荧光分子探针容易受到 $\mathrm{Cd}^{2+}$ 的干扰，所以开发能够对 $\mathrm{Zn}^{2+} / \mathrm{Cd}^{2+}$ 分别检测的苂光分 子探针也是化学家和生物学家重点关注的课题之一, 且 目前已取得了较大的进展 ${ }^{[64]}$, 如上述的探针 17 和探针 34. 总的来说, 发展高选择性的 $\mathrm{Zn}^{2+}$ 荧光分子探针还是
未来趋势，笔者认为新型的下一代 $\mathrm{Zn}^{2+}$ 荧光分子探针 应具有: (1)易配位且配位能力强; (2)能在生理 $\mathrm{pH}$ 范围 检测痕量 $\mathrm{Zn}^{2+}$; (3) $\mathrm{Zn}^{2+}$ 在苂光敏感方面具有高选择性, 其他金属离子的荧光干扰极小或非常有限或者可掩蔽; (4) $\mathrm{Zn}^{2+}$ 作用敏感且反应速度快; (5)良好的细胞渗透性, 并使其在不伤害活体细胞的情况下发出荧光; (6)荧光效 率高等特点. 总之，虽然研究者已经开发和研制出了很 多 $\mathrm{Zn}^{2+}$ 荧光分子探针，但为达到更高的检测要求，目前 仍需开发更多更好的新荧光团和识别配体 ${ }^{[65]}$. 今后，灵 敏度高、选择性专一、光稳定性和水溶性良好等优点的 $\mathrm{Zn}^{2+}$ 苂光探针的设计及应用研究仍是该领域科研工作 者关注的焦点和难点. 此外, 生物技术、纳米技术和超 分子化学的交叉融合，也将给开发和制备新型 $\mathrm{Zn}^{2+}$ 苂 光分子探针带来新的启示.

\section{References}

[1] Vallee, B. L.; Falchuk, K. H. Phys. Rev. 1993, 73, 79.

[2] Frederickson, C. J.; Koh, J. Y.; Bush, A. I. Nat. Rev. Neurosci. 2005, 6, 449 .

[3] Bush, A. I.; Pettingell, W. H.; Multhaup, G.; Paradis, M. D.; Vonsattel, J. P.; Gusella, J. F.; Beyreuther, K.; Masters, C. L.; Tanzi, R. E. Science 1994, 265, 1464.

[4] Kikuchi, K.; Komatsu, K.; Nagano, T. Curr. Opin. Chem. Biol. 2004, $8,182$.

[5] Valeur, B.; Leray, I. Coord. Chem. Rev. 2000, 205, 3.

[6] Frederickson, C. J.; Kasarskis, E. J.; Ringo, D.; Frederickson, R. E. J. Neurosci. Meth. 1987, 20, 91.

[7] Fahrni, C. J.; O'Halloran, T. V.; J. Am. Chem. Soc. 1999, 121, 11448.

[8] Pearce, D. A.; Jotterand, N.; Carrico, I. S.; Imperial, B. J. Am. Chem. Soc. 2001, 123, 5160.

[9] Mikata, Y.; Wakamatsu, M.; Yano, S. Dalton Trans. 2005, 545.

[10] Royzen, M.; Durandin, A.; Young, V. G.; Geacintov, N. E.; Canary, J. W. J. Am. Chem. Soc. 2006, 128, 3854.

[11] Zhang, Y.; Guo, X. F.; Jia, L. H.; Qian, X. H. Prog. Chem. 2008, 20, 1945 (in Chinese).

(张宇, 郭祥峰, 贾丽华, 钱旭红, 化学进展, 2008, 20, 1945.)

[12] Wang, H. H.; Gan, Q.; Wang, X. J.; Xue, L.; Liu, S. H.; Jiang, H. Org. Lett. 2007, 9, 4995.

[13] Zhang, C. L.; Zhang, Y. M.; Chen, Y. C.; Xie, Z. J.; Liu, Z. P.; Dong, X. D.; He, W. J.; Shen, C.; Guo, Z. J. Inorg. Chem. Commun. 2011, 14, 304.

[14] You, Q. H.; Chan, P. S.; Chan, W. H.; Hau, S. C. K.; Lee, A. W. M.; Mark, N. K.; Mark, T. C. W.; Wong, R. N. S. RSC Adv. 2012, 2,11078 .

[15] Hirano, T.; Kikuchi, K.; Urano, Y.; Higuchi, T.; Nagano, T. J. Am. Chem. Soc. 2000, 122, 12399.

[16] [16] Burdette, S. C.; Walkup, G. K.; Spingler, B.; Tsien, R. Y.; Lippard, S. J. Am. Chem. Soc. 2001, 123, 7831.

[17] Nolan, E. M.; Burdette, S. C.; Harvey, J. H.; Hilderbrand, S. A.; Lippard, S. J. Inorg. Chem. 2004, 43, 2624.

[18] Chang, C. J.; Nolan, E. M.; Jaworski, J.; Okamoto, K. I.; Hayashi, Y.; Sheng, M.; Lippard, S. J. Inorg. Chem. 2004, 43, 6774.

[19] Nolan, E. M.; Lippard, S. J. Inorg. Chem. 2004, 43, 8310.

[20] Nolan, E. M.; Ryu, J. W.; Jaworski, J.; Feazell, R. P.; Sheng, M.; Lippard, S. J. J. Am. Chem. Soc. 2006, 128, 15517. 
[21] Nolan, E. M.; Jaworski, J.; Okamoto, K. I., Hayashi, Y.; Sheng, M.; Lippard, S. J. J. Am. Chem. Soc. 2005, 127, 16812.

[22] Zhang, X. A.; Hayes, D.; Smith, S. J.; Friedle, S.; Lippard, S. J. J. Am. Chem. Soc. 2008, 130, 15788.

[23] Buccella, D.; Horowitz, J. A.; Lippard, S. J. J. Am. Chem. Soc. 2011, 133, 4101.

[24] Lim, N. C.; Yao, L.; Freake, H. C.; Bruckner, C. Bioorg. Med. Chem. Lett. 2003, 13, 2251.

[25] Lim, N. C.; Schuster, J. V.; Porto, M. C.; Tanudra, M. A.; Yao. L.; Freake, H. C.; Bruckner, C. Inorg. Chem. 2005, 44, 2018.

[26] Su, Z.; Chen, K. Y.; Guo, Y.; Qi, H. P.; Yang, X. F.; Zhao, M. L. J. Fluoresc. 2010, 20, 851.

[27] Koutaka, H.; Kosuge, J. I.; Fukasaku, N.; Hirano, T.; Kikuchi, K.; Urano, Y.; Kojima, H.; Nagano, T. Chem. Pharm. Bull. 2004, 52, 700.

[28] Wu, Y. K.; Peng, X. J.; Guo, B. C.; Fan, J. L.; Zhang, Z. C.; Wang, J. Y.; Cui, A. J.; Gao, Y. L. Org. Biomol. Chem. 2005, 3, 1387.

[29] Wang, J. B.; Xiao, Y.; Zhang, Z. C.; Qian, X. H.; Yang, Y. Y.; Qin, X. J. Mater. Chem. 2005, 15, 2836.

[30] Xu, Z. C.; Baek, K. H.; Kim, H. N.; Cui, J. N.; Qian, X. H.; Spring, D. R.; Shin, I.; Yoon, J. J. Am. Chem. Soc. 2010, 132, 601.

[31] Jiang, W.; Fu, Q.; Fan, H.; Wang, W. Chem. Commun. 2008, 259.

[32] Majzoub, A. E.; Cadiou, C.; Olivier, I. D.; Tinant, B.; Chuburu, F. Inorg. Chem. 2011, 50, 4029.

[33] Kwon, J. E.; Lee, S.; You, Y. M.; Baek, K. H.; Ohkubo, K.; Cho, J.; Fukuzumi, S.; Shin, I.; Park, S. Y.; Nam, W. Inorg. Chem. 2012, 51,8760 .

[34] Gee, K. R.; Zhou, Z. L.; That, D. T.; Sensi, S. L.; Weiss, J. H. Cell Calcium 2002, 31, 245.

[35] Sensi, S. L.; That, D. T.; Weiss, J. H.; Rothe, A.; Gee, K. R. Cell Calcium 2003, 34, 281.

[36] Gee, K. R.; Zhou, Z. L.; Qian, W. J.; Kennedy, R. J. Am. Chem. Soc. 2002, 124, 776.

[37] Gunnlaugsson, T.; Lee, T. C.; Parkesh, R. Org. Biomol. Chem. 2003, 1,3265 .

[38] Roussakis, E.; Voutsadaki, S.; Pinakoulaki, E.; Sideris, D. P.; Tokatlidis, K.; Katerinopoulos, H. E. Cell Calcium 2008, 44, 270.

[39] Tang, Y. Y.; Luo, C. H.; Wu, C. Y.; Shen, G. L.; Yu, R. Q. Acta Chim. Sinica 2007, 65, 1229 (in Chinese).

(唐友云, 罗春花, 吴朝阳, 沈国励, 俞汝勤, 化学学报, 2007, $65,1229$.

[40] Tang, B.; Huang, H.; Xu, K. H.; Tong, L.; Yang, G. W.; Liu, X.; An, L. G. Chem. Commun. 2006, 3609.

[41] Kiyose, K.; Kojima, H.; Urano, Y.; Nagano, T. J. Am. Chem. Soc. 2006, $128,6548$.

[42] Guo, Z. Q.; Kim, G. H.; Shin, I.; Yoon, J. Biomaterials 2012, 33,
7818.

[43] Yang, X. B.; Yang, B. X.; Ge, J. F.; Xu, Y. J.; Xu, Q. F.; Liang, J.; Lu, J. M. Org. Lett. 2011, 13, 2710.

[44] Zhang, Q. Q.; Yang, B. Y.; Sun, R.; Ge, J. F.; Xu, Y. J.; Li, N. J.; Lu, J. M. Sens. Actuators, B 2012, 171 172, 1001.

[45] Maruyama, S.; Kikuchi, K.; Hirano, T.; Urano, Y.; Nagano, T. J. Am. Chem. Soc. 2002, 124, 10650.

[46] Lim, N. C.; Bruckner, C. Chem. Commun. 2004, 1094.

[47] Komatsu, K.; Urano, Y.; Kojima, H.; Nagano. T. J. Am. Chem. Soc. 2007, 129, 13447.

[48] Atilgan, S.; Ozdemir, T.; Akkaya, E. U. Org. Lett. 2008, 10, 4065.

[49] Lu, C. L.; Xu, Z. C.; Cui, J. N.; Zhang, R.; Qian, X. H. J. Org. Chem. 2007, 72, 3554 .

[50] Hanaoka, K.; Muramatsu, Y.; Urano, Y.; Terai, T.; Nagano, T. Chem. Eur. J. 2010, 16, 568.

[51] Zhang, Y.; Guo, X. F.; Si, W. X.; Jia, L. H.; Qian, X. H. Org. Lett. 2008, 10, 473.

[52] Du, J. J.; Fan, J. L.; Peng, X. J.; Li, H. L.; Sun, S. G. Sens. Actuators, B 2010, 144, 337.

[53] Meng, X. M.; Wang, S. X.; Li, Y. M.; Zhu, M. Z.; Guo, Q. X. Chem. Commun. 2012, 48, 4196.

[54] Xie, G. Q.; Shi, Y. J.; Hou, F. P.; Liu, H. Y.; Huang, L.; Xi, P. X.; Chen, F. J.; Zeng, Z. Z. Eur. J. Inorg. Chem. 2012, 327.

[55] Sahoo, H. J. Photochem. Photobiol. C 2011, 12, 20.

[56] Han, Z. X.; Zhang, X. B.; Li, Z.; Gong, Y. J.; Wu, X. Y.; Jin, Z.; He, C. M.; Jian, L. X.; Zhang, J.; Shen, G. L.; Yu, R. Q. Anal. Chem. 2010, 82, 3108.

[57] Xu, Z.; Kim, G. H.; Han, S. J.; Jou, M. J.; Lee, C.; Shin, I.; Yoon, J. Tetrahedron 2009, 65, 2307.

[58] Qian, F.; Zhang, C.; Zhang, Y.; He, W.; Gao, X.; Hu, P.; Guo, Z. J. Am. Chem. Soc. 2009, 131, 1460.

[59] Zhao, C. C.; Zhang, Y. L.; Feng, P.; Cao, J. Dalton Trans. 2012, 41, 831.

[60] Woo, H; You, Y. M.; Kim, T. H.; Jhon, G. J.; Nam, W. W. J. Mater. Chem. 2012, 22, 17100.

[61] Xu, Y. Q.; Pang, Y. Dalton Trans. 2011, 40, 1503.

[62] Taki, M.; Wolford, J. L.; O'Halloran, T. V. J. Am. Chem. Soc. 2004, 126, 712 .

[63] Fahrni, C. J.; Henary, M. M. J. Phys. Chem. A 2002, 106, 5210.

[64] Jia, J.; Tang, Q.; He, Y. F.; Zhang, M. Y.; Xing, G. W. Chin. J. Org. Chem. 2012, 32, 1803 (in Chinese). (㚘佳, 唐茜, 何颖芳, 张梦雨, 刑国文, 有机化学, 2012, 32, 1803.)

[65] Xu, Z. C.; Yoon, J. Y.; Spring, D. R. Chem. Soc. Rev. 2010, 39, 1996. 